\title{
Evolution of metabolic risk factors over a two-year period in a cohort of first episodes of psychosis
}

Miquel Bioque ${ }^{a}$, M. a Paz García-Portilla ${ }^{b, *}$, Clemente García-Rizo ${ }^{c, *}$, Bibiana Cabrera ${ }^{a}$, Antonio Lobo ${ }^{d}$, Ana González-Pinto ${ }^{\text {e }}$, Covadonga M. a Díaz-Caneja ${ }^{f}$, lluminada Corripio ${ }^{g}$, Eduard Vieta ${ }^{\text {h, Josefina }}$ Castro-Fornieles ', Julio Bobes ${ }^{\text {b }}$, Miguel Gutiérrez Fraile ${ }^{j}$, Roberto Rodriguez-Jimenez ${ }^{k}$, Gisela Mezquida ${ }^{\mathrm{a}}$, Adrián Llerena ', Jeronimo Saiz-Ruiz ${ }^{\mathrm{m}}$, Miguel Bernardo ${ }^{\mathrm{n}, * *}$ and PEPs GROUP***.

a Barcelona Clínic Schizophrenia Unit, Hospital Clínic de Barcelona, Barcelona, Spain; Centro de Investigación Biomédica en Red de Salud Mental (CIBERSAM), Spain.

${ }^{b}$ Department of Psychiatry, University of Oviedo, Oviedo, Spain; Centro de Investigación Biomédica en Red de Salud Mental (CIBERSAM), Spain.

c Barcelona Clínic Schizophrenia Unit, Hospital Clínic de Barcelona, Barcelona, Spain; Centro de Investigación Biomédica en Red de Salud Mental (CIBERSAM), Spain; Institut d'investigacions Biomèdiques August Pi i Sunyer (IDIBAPs), Barcelona, Spain.

d Department of Medicine and Psychiatry, University of Zaragoza, Instituto de Investigación Sanitaria Aragón (IIS Aragón), Zaragoza, Spain.

e BIOARABA Health Research Institute, OSI Araba, University Hospital, University of the Basque Country, Vitoria, Spain; Centro de Investigación Biomédica en Red de Salud Mental (CIBERSAM), Spain.

${ }_{\mathrm{f}}$ Department of Child and Adolescent Psychiatry, Hospital General Universitario Gregorio Marañón, liSGM, School of Medicine, Universidad Complutense, Madrid, Spain; Centro de Investigación Biomédica en Red de Salud Mental (CIBERSAM), Spain.

${ }^{\mathrm{g}}$ Department of Psychiatry, Hospital de Sant Pau, Barcelona, Spain; Centro de Investigación Biomédica en Red de Salud Mental (CIBERSAM), Spain.

${ }^{h}$ Psychiatry and Department, Hospital Clínic de Barcelona, University of Barcelona, Barcelona, Spain; Institut d'Investigacions Biomèdiques August Pi i Sunyer (IDIBAPS), Barcelona, Spain; Centro de Investigación Biomédica en Red de Salud Mental (CIBERSAM), Spain.

i Child and Adolescent Psychiatry and Psychology Department, SGR489, Hospital Clinic of Barcelona, Institute of Neurosciences, University of Barcelona, Barcelona, Spain; Centro de Investigación Biomédica en Red de Salud Mental (CIBERSAM), Spain.

${ }^{j}$ Department of Psychiatry, Hospital Santiago Apóstol, University of the Basque Country, Vitoria, Spain; Centro de Investigación Biomédica en Red de Salud Mental (CIBERSAM), Spain.

${ }^{k}$ Instituto de Investigación Hospital 12 de Octubre (imas12), Madrid, Spain; Centro de Investigación Biomédica en Red de Salud Mental (CIBERSAM), Spain.

' CICAB-CAIBER Centro de Investigación Clínica, Hospital Universitario. Servicio Extremeño de Salud SES, Facultad de Medicina Universidad de Extremadura, Badajoz, Spain; Centro de Investigación Biomédica en Red de Salud Mental (CIBERSAM), Spain.

${ }^{m}$ Department of Psychiatry, Hospital Universitario Ramón y Cajal, IRYCIS, Universidad de Alcalá, Madrid, Spain; Centro de Investigación Biomédica en Red de Salud Mental (CIBERSAM), Spain.

n Barcelona Clínic Schizophrenia Unit, Neuroscience Institute, Hospital Clínic of Barcelona, Barcelona, Spain; Department of Psychiatry and Clinical Psychobiology, University of Barcelona, Barcelona, Spain; Institut $\mathrm{d}^{\prime}$ Investigacions Biomèdiques August Pi i Sunyer (IDIBAPS), Barcelona, Spain; Centro de Investigación Biomédica en Red en Salud Mental (CIBERSAM), G04, Barcelona, Spain.

*The second and the third authors (MPG-P, CG-R) contributed equally to this work.

** Corresponding author:

Miguel Bernardo, MD, PhD

Barcelona Clínic Schizophrenia Unit, Neuroscience Institute, Hospital Clínic de Barcelona, Barcelona, Spain.

Tel.: +34932275400 (X 3142)

Fax: +34932275548

E-mail address: $\underline{\text { bernardo@clinic.ub.es }}$

*** PEPs GROUP: Ana Meseguer, Sílvia Amoretti, Carmen Moreno, Mara Parellada, Anna Alonso-Solís, Mireia Rabella, Mónica Martínez- Cengotitabengoa, Itxaso González-Ortega, José Luis Díaz, Mạ Fe Barcones, Maria Jose Escarti, Carlos Cañete, Purificación Salgado, Iris Cáceres, Carla Torrent, Ivette Morilla, Inmaculada Baeza, Elena de la Serna, Fernando Contreras, Auria Albacete, Leticia García-Alvarez, Lorena de la Fuente, José Ignacio Eguiluz, Rafael Segarra, Isabel Morales-Muñoz, losune Torio, Judith Usall, Anna Butjosa, Salvador Sarró, Ramón Landín-Romero, Ángela Ibáñez, Manuel J Cuesta and Vicent Balanzá-Martínez. 


\section{Abstract}

Patients with a first episode of psychosis (FEP) display a broad range of metabolic risk factors related to the development of diverse medical comorbidities. Initial stages of these disorders are essential in understanding the increased vulnerability of developing cardiometabolic disturbances, associated with a reduced life expectancy. This study aimed to evaluate the metabolic profile of a cohort of patients with a FEP and its evolution during a two year follow-up, as well as the factors that influence the changes in their metabolic status.

16 participating centers from the PEPs Project recruited 335 subjects with a FEP and 253 matched healthy controls, aged 9-35 years. We investigated a set of anthropometric measures, vital signs and laboratory data obtained from each participant over two years in a prospective, naturalistic study.

From the beginning of the study the FEP group showed differences in the metabolic profile compared to the control group, together with a progressive worsening in the major part of the analyzed variables during the follow-up period, with higher rates of obesity and metabolic syndrome. Certain risk factors were related to determinate clinical variables such as male gender, the presence of affective symptoms or an early onset or to treatment variables such as the use of antipsychotic polypharmacy, antidepressants or mood stabilizers.

Our results highlight the extremely high risk of patients at early phases of schizophrenia and other psychotic disorders of developing cardiovascular comorbidity and the fast worsening of the metabolic profile during the first two years. 


\section{Introduction}

Patients with a first episode of psychosis (FEP) display a wide array of metabolic disturbances (Fleischhacker et al., 2013), which over time might predict the development of diverse medical conditions, such as metabolic syndrome (MetS) or cardiovascular diseases (CVD). Those medical comorbidities seem to underlie the increased mortality in those patients detected even at the onset of a mental disorder (Laursen et al., 2013; Nordentoft et al., 2013). Part of this increased risk might also be related to the metabolic side effects of antipsychotics, already present after few weeks of treatment (Fernandez-Egea et al., 2011; Tek et al., 2016).

Initial stages of psychotic disorders are essential in understanding the increased risk of developing metabolic disturbances (Fernandez-Egea et al., 2009; Perez-Iglesias et al., 2014). Two meta-analyses reflect that the risk for MetS is low in FEP but increases over time (Mitchell et al., 2013; Mitchell et al., 2011), with high prevalence in chronic patients (Arango et al., 2008). The determination of MetS rates at initial stages might underscore the risk of developing CVD, so further analysis must be implemented (Garcia-Rizo et al., 2017). At initial stages, glucose abnormalities are the most replicated findings (Anto et al., 2017; Garcia-Rizo et al., 2016; Greenhalgh et al., 2016; Perry et al., 2016; Pillinger et al., 2017; Ryan et al., 2003; Spelman et al., 2007). Besides, other CVD risk factors have been assessed: (i) blood pressure, through increased pulse pressure (Fernandez-Egea et al., 2009); (ii) lipid profile has been reported to be altered (Keinanen et al., 2015) or subclincal (Misiak et al., 2017), while other studies did not find differences(Kirkpatrick et al., 2010); and (iii) abdominal obesity (Ryan et al., 2004), but other studies failed to replicate (Fernandez-Egea et al., 2009; Keinanen et al., 2015). In this context, the study of the population with a FEP is of great interest because it avoids the effect of confounding variables, such as somatic comorbidities, prolonged antipsychotic treatment or chronicity (Bernardo and Bioque, 2014; Bernardo et al., 2013).

The PEPs Project was a multicenter, prospective, longitudinal, naturalistic study, conducted in 16 research sites in Spain designed to follow a cohort of 335 subjects with a FEP, matched with 253 healthy controls (Bernardo et al., 2013; Bioque et al., 2016). The aim of the present study was to evaluate the metabolic profile of patients at the FEP and its evolution during the two year follow-up, aiming to identify the factors that influence in these early changes. This study offers a unique opportunity to extend previous research by investigating the prevalence of metabolic abnormalities in a real-world cohort of patient with a FEP treated with commonly-used drugs during a follow-up of two years.

\section{Methods}

\section{Subjects}

During the recruitment period (2009-2012), every patient who met the inclusion criteria that was attended at the PEPs project participating sites facilities was invited to participate in the study, either inpatient or outpatient. The rationale and the complete clinical protocol used in the PEPs project were previously published (Bernardo et al., 2013) (free text available both in English and Spanish).

The inclusion criteria for patients were: presence of a FEP in the last 12 months, age between 7 and 35, and speak Spanish correctly. The Spanish translation of the K-SADS-PL (Kaufman et al., 1997) was used to assess current and past psychopathology in children and adolescents according to DSM-IV criteria (American Psychiatric Association (Washington), 1994), and the SCID-I \& II, with a Spanish translation available, for adults (First et al., 1994, 1999). In order to retrospectively characterize and date the initial symptoms of a psychotic illnesses the Symptom Onset in Schizophrenia (SOS) inventory was used (Perkins et al., 2000). 
The exclusion criteria for patients were: (1) mental retardation according to DSM-IV criteria (American Psychiatric Association (Washington), 1994), (2) history of head trauma with loss of consciousness and (3) presence of an organic disease with mental repercussions.

Healthy controls were matched by age $( \pm 10 \%)$, gender and parental socio-economic status (SES), measured by the Hollingshead-Redlich scale ( \pm 1 level). They also had to speak Spanish fluently. The exclusion criteria for controls were the same as for patients plus having a personal antecedent of psychotic and/or major affective disorder and having a first degree relative with psychotic disorder history.

With the above mentioned criteria, a cohort of 335 subjects who have suffered a FEP within the previous 12 month and 253 healthy controls were included in the PEPs Project, with an age between 9 and 35 years. 198 patients and 158 control subjects were kept in the study until the two year follow-up final visit.

Being a naturalistic study, there were no specific guidelines for treatments, so patients received antipsychotic treatment based on the clinician's choice. Dosing, co-medications or treatment changes were based on clinical necessity. Following the inclusion/exclusion criteria, treatment with antipsychotics did not exceed 12 months at study entry, with a mean duration of untreated psychosis (DUP) of 106.21 days (Bernardo et al., 2017). As the majority of the participating centres were tertiary university hospitals a large majority of the patients included in the study were recruited during their first hospitalization, when the first antipsychotic treatment was indicated. The major part of the patients $(n=304,90.7 \%)$ were under antipsychotic treatment by the time they were included in the study, with a mean of 54.08 days taking antipsychotic treatment (Bioque et al., 2016). Only a small proportion ( $n=49$, $14.6 \%$ of the sample) had been taking antipsychotic for more than three months before the inclusion. A previous report gave a full description of the psychopharmacological treatment used in this study (Bioque et al., 2016).

The study was approved by the investigation ethics committees of all participating centers and informed consent was obtained from all participants or legal guardians.

\section{Study assessments and biochemical determinations}

At baseline, a complete medical history was taken. Body weight, blood pressure and waist circumference were assessed at baseline and at 2, 6, 12 and 24 months visits. Laboratory data was obtained at every visit in patients and at baseline and at 24 months in controls. In all the participating sites, blood glucose, total cholesterol, high density lipoprotein (HDL) cholesterol, low density lipoprotein (LDL) cholesterol, and triglycerides (TG) were directly analyzed by enzymatic procedures with an Automatic Chemical Analyzer. Glycated hemoglobin was analyzed by high-performance liquid chromatography (HPLC). The reference values at each site were recorded in a common database called GIDSAM, where individual values were homogenized and included (Bernardo et al., 2013).

\section{Metabolic and cardiovascular risk assessment}

Taking each individual's anthropometric measures, vital signs and laboratory data, the presence of MetS and/or obesity was established for each participant at baseline and 24 month's visit. As subjects included in the PEPs project were aged from 9 to 35, both conditions were defined with available criteria which have different definitions for underage and adult. Thus, the presence of Mets was defined using 
the International Diabetes Foundation (IDF) criteria (Alberti et al., 2005; Zimmet et al., 2007). In subjects aged 10 to 16 years, the MetS criteria were abdominal obesity $\geq 90$ th percentile (or adult cut-off if lower), fasting glucose $\geq 100 \mathrm{mg} / \mathrm{dL}$, triglycerides $\geq 150 \mathrm{mg} / \mathrm{dL}, \mathrm{HDL}$ cholesterol $<40 \mathrm{mg} / \mathrm{dL}$ and blood $\geq$ $130 / 85 \mathrm{mmHg}$. In subjects $\geq 16$ years the criteria were abdominal obesity $>94 \mathrm{~cm}$ in men and $>80 \mathrm{~cm}$ in women, fasting glucose $\geq 100 \mathrm{mg} / \mathrm{dL}$, triglycerides $\geq 150 \mathrm{mg} / \mathrm{dL}$, HDL cholesterol $<40 \mathrm{mg} / \mathrm{dL}$ in men and $<50 \mathrm{mg} / \mathrm{dL}$ in women and blood pressure $\geq 130 / 85 \mathrm{mmHg}$, or being under pharmacological treatment for any of the previous conditions. In all subjects, the presence of the abdominal obesity criteria was mandatory, plus 2 of the other 4 criteria (Alberti et al., 2005; Zimmet et al., 2007).

Also the overweight/obesity definition was different for underage or adult subjects, following the WHO charts (http://www.who.int/growthref/who2007 bmi for age/en/).

Diabetes was considered present if the participant was under treatment with insulin or oral hypoglycemic agents or whether fasting blood glucose exceeded $126 \mathrm{mg} / \mathrm{dl}$.

\section{Statistical analysis}

Differences in categorical variables were assessed using a two-tailed Chi-square test. Baseline differences on continuous variables with approximately normal distributions were assessed using a twotailed $t$ test.

A multivariate analysis of covariance (MANCOVA) was conducted to compare baseline anthropometric, vital signs and metabolic measures between patient and control groups. The number of days of the antipsychotic treatment previous to the baseline assessment was used a covariate in this analysis, as we found positive correlations between the length of previous antipsychotic treatment and some of the metabolic measures.

Differences between cases and controls on continuous variables at the endpoint were assessed using a lineal mixed model.

Within the FEP group, a one-way repeated measures ANOVA was conducted to compare patient's anthropometric, vital signs and metabolic measures between every visit.

A mixed between-within subjects analysis of variance was conducted to assess the impact of gender, diagnosis (affective vs. non-affective psychoses) and age of onset (underage vs. adult) on these measures. A Chi-square test for independence was used to explore the relationship between gender, diagnosis, age of onset, antipsychotic treatment, antipsychotic polytherapy, obesity, significant body weight gain (>7\%) or MetS at the study final visit.

The relationship between the metabolic outcomes and antipsychotic mean daily doses (in chlorpromazine equivalents) was investigated using Pearson correlation coefficient.

A value of $p<0.05$ was taken to be statistically significant in all analysis. Data was managed and analyzed with the IBM SPSS Statistics v.23.

\section{Results}

Baseline clinical characteristics, anthropometric, vital signs and metabolic measures 
335 patients with a FEP and 253 healthy controls completed the baseline visit. $57(17,6 \%)$ patients and $32(12.6 \%)$ controls were underage. Demographic and clinical characteristics and baseline metabolic measures are presented in Table 1.

(Table 1 about here)

At baseline, the FEP group presented statistically significant higher total and LDL cholesterol and lower HDL cholesterol mean levels (Table 1). At this point, patients and control showed differences in two of the five IDF MetS criteria (glucose and HDL cholesterol).

\section{Anthropometric, vital signs and metabolic measures in the follow-up visits}

After two years, the FEP group showed higher mean levels of glucose, triglycerides, diastolic blood pressure and lower HDL cholesterol, together with higher body weight, BMI and waist circumference measures (table 2). There were differences between groups in overweight, obesity and MetS rates, with statistical significant differences in 4 of the 5 IDF MetS criteria.

(Table 2 about here)

Within the group of FEP, there were statically significant increases of glycated hemoglobin, triglycerides, total cholesterol, HDL cholesterol, body weight, BMI and abdominal circumference measures thorough the five follow-up visits (table 3), with a moderate to large effect size, according to commonly used guidelines (Cohen, 1988), these increases showed. The proportion of subjects with overweight and obesity also significantly increased across the follow-up.

(Table 3 about here)

A total of $55.1 \%(103 / 187)$ of the FEP subjects gained $\geq 7 \%$ of body weight during the 2 -years follow-up. This relevant body weight gain was not associated with diagnosis, gender or age of onset.

\section{Effect of gender}

At baseline, the male subgroup of FEP patients showed statistically significant higher systolic blood pressure mean measures (122.91 vs. $113.78 \mathrm{mmHg}, \mathrm{t}=-6.02, \mathrm{p}<0.001$ ) and lower HDL cholesterol mean levels (47.11 vs. $54.43 \mathrm{mg} / \mathrm{dL}, \mathrm{U}=5721, \mathrm{p}=0.002$ ). While a larger proportion of male patients filled the IDF MetS criteria of hypertension (30 vs. $10.57 \%, \chi 2=14.57, p<0.001$ ), more female patients fulfilled criteria of abdominal circumference (60.71 vs. $21.02 \%, \chi 2=39.62, p<0.001)$ and low HDL cholesterol (45.78 vs. $23.62 \%, \chi 2=13.19, p=0.001$ ). 
After two years, the male group of FEP patients kept showing statistically significant higher systolic blood pressure mean measures (123.89 vs. $114.08 \mathrm{mmHg}, \mathrm{t}=-4.67, \mathrm{p}<0.001$ ), lower HDL cholesterol mean levels ( 44 vs. $55.20 \mathrm{mg} / \mathrm{dL}, \mathrm{t}=5.51, \mathrm{p}<0.001$ ) and a larger proportion the IDF MetS hypertension criteria ( 31.29 vs. $13.55 \%, \chi 2=6.69, p=0.007$ ). Besides, the male group also showed statistically significant higher diastolic blood pressure mean measures ( $72.25 \mathrm{vs} .68 .86 \mathrm{mmHg}, \mathrm{t}=-2.17 \mathrm{p}<0.036), \mathrm{LDL}$ cholesterol mean levels (107.13 vs. $94.62 \mathrm{mg} / \mathrm{dL}, \mathrm{t}=-2.68, \mathrm{p}=0.008)$ and glycated hemoglobin mean levels $(5.40$ vs. $5.17, \mathrm{U}=4894.5, \mathrm{p}<0.001$ ). On the other hand, female patients kept showing a larger proportion of IDF MetS criteria of abdominal circumference (62.96 vs. $39.51 \%, \chi 2=12.67, p<0.001$ ).

A mixed between-within subjects analysis of variance showed no significant interaction between gender and BMI, body weight, waist circumference, glycated hemoglobin, total cholesterol and triglycerides, but there was a substantial main effect for time $(p<0.05)$, suggesting that all these parameters increased during the follow up period in a similar way in both genders (Figures $1 \mathrm{~A}-\mathrm{E}$, supplemental info 1 ). Male patients showed statistically significant major decreases of HDL cholesterol mean values than women over the study (Wilks' Lambda $=0.9, F=2.97, p=0.023$ ) (Figure 1F).

(Figure 1 about here)

We found no significant association between gender and the presence of obesity $(\chi 2=0.63, p=0.28$, phi=$0.55)$, body weight gain $>7 \%(\chi 2=0.22, p=0.64$, phi $=-0.03)$, or MetS $(\chi 2=0.12, p=0.92, p h i=-0.029)$ at the study final visit.

\section{Effect of diagnosis}

Two hundred and eighty patients (83.6\%) were diagnosed of "non-affective psychosis" and 55 subjects (16.4\%) were diagnosed of DSM-IV "affective psychosis" (unipolar depression or bipolar disorder with psychotic features and schizoaffective disorder). At baseline, the group of patients with an affective psychosis showed a significant proportion of subjects with obesity $(15.4$ vs. $6.61 \%, \chi 2=4.55, p=0.048)$ and lower HDL cholesterol mean levels ( $44.31 \mathrm{vs.} 50.28 \mathrm{mg} / \mathrm{dL}, \mathrm{t}=2.71, \mathrm{p}=0.007$ ), compared to the group of patients with a "non-affective psychoses". There were no differences in the proportion of cases with MetS.

After two years the proportion of cases with MetS was significantly higher in the affective psychosis group (26.66 vs. $11.57 \%, \chi 2=4.41, p=0.046$, phi=0.17). We found no significant association between gender and the presence of obesity $(\chi 2=3.23, p=0.079$, phi=-0.13) or body weight gain $>7 \%(\chi 2=0.07$, $\mathrm{p}=0.85$, phi=0.02).

We found no significant interaction between diagnosis and any of the CV risk factors measures, suggesting similar evolution both in affective and non-affective psychoses (supplemental info 2 ).

\section{Effect of the age of onset}

Fifty-seven subjects were underage ( $<18$ years) when their FEP started. At baseline, this subgroup showed lower mean body weight (61.68 vs. $70.39 \mathrm{~kg}, \mathrm{t}=-4.27, \mathrm{p}<0.001)$, BMI $\left(21.9 \mathrm{vs} .23 .8 \mathrm{~kg} / \mathrm{m}^{2}, \mathrm{t}=-\right.$ 3.01, $\mathrm{p}=0.002)$ and abdominal perimeter $(79.58 \mathrm{~cm}$ vs. $87.12, \mathrm{t}=-4.02, \mathrm{p}<0.001)$. They also showed 
statistically significant lower total cholesterol (152.80 vs. $163.87 \mathrm{mg} / \mathrm{dL}, \mathrm{U}=8278, \mathrm{p}=0.041)$, LDL cholesterol ( 88.16 vs. $27.18 \mathrm{mg} / \mathrm{dL}, \mathrm{U}=6307, \mathrm{p}=0.048$ ) and glycated hemoglobin mean levels (5.05 vs. $5.23 \%, t=-2.25, p=0.025)$. After two years, this subpopulation stilled showed significant lower total cholesterol mean levels ( 161.10 vs. $173.35 \mathrm{mg} / \mathrm{dL}, \mathrm{t}=-1.99, \mathrm{p}=0.047$ ).

Patients with early onset showed a statistically significant major increase in fasting glucose mean values along the study (Wilks' Lambda $=0.91, F=3.19, p=0.017$; supplemental info 3 ). We found no statistical association between the age of onset and the probability of presenting obesity $(\chi 2=0.026, p=1.0$, phi=$0.012)$, body weight gain $>7 \%(\chi 2=2.17, p=0.18$, phi $=-0.11)$ or MetS $(\chi 2=0.13, p=0.77$, phi $=-0.03)$ at the two-year visit.

\section{Psychopharmacological treatment}

Psychopharmacological treatment registered in the baseline and final visits is resumed in table 4.

(Table 4 about here)

At baseline, patients had been treated with antipsychotics a mean of 54.08 days. Thirty-one patients (9.2\%) were not receiving antipsychotics, including those never treated and those who had already discontinued previous treatments. Compared to the subgroup of patients who were under antipsychotic treatment, this subgroup of patients who were not receiving antipsychotics at baseline showed significant lower rater of diabetes $(0.35 \%$, vs. $4.16 \%, \chi 2=4.76, p=0.029)$ and lower levels of LDL cholesterol ( 94.40 vs. $106.15 \mathrm{mg} / \mathrm{dL}, \mathrm{t}=-1.98, \mathrm{p}=0.049$ ) and waist circumference $(80.95$ vs. $86.28 \mathrm{~cm}$, $\mathrm{t}=1.99, \mathrm{p}=0.047)$. Mean diastolic blood pressure were significantly higher in the non-treated group (75.77 vs. $71.47 \mathrm{mmHg}, \mathrm{U}=3883, \mathrm{p}=0.033$ ).

There were no statistical differences in any metabolic parameter between the groups of patients being treated or not with antipsychotics ( $n=20 / 116 ; 17.2 \%)$ at the end of the study.

Patients receiving an antipsychotic polytherapy regimen at the beginning of the study presented statistically significant higher mean body weight $(72.28$ vs. $68.45 \mathrm{~kg}, \mathrm{t}=2.02, \mathrm{p}=0.044)$, BMI (24.69 vs. $\left.23.28 \mathrm{~kg} / \mathrm{m}^{2}, \mathrm{t}=2.49, \mathrm{p}=0.015\right)$, glucose levels $(87.08 \mathrm{vs} .83 .48 \mathrm{mg} / \mathrm{dL}, \mathrm{t}=2.07, \mathrm{p}=0.039)$ and glycated hemoglobin levels ( 24.69 vs. $23.28 \mathrm{~kg} / \mathrm{m}^{2}, \mathrm{t}=-2.04, \mathrm{p}=0.043$ ). Those differences between the antipsychotic monotherapy vs. polytherapy groups were not maintained at the end of the follow up period.

At baseline, higher body weight was statistically associated with higher baseline antipsychotic dose $(r=0.12, p=0.042)$. At the 2-year visit there wasn't any significant correlation between the antipsychotic dosage and metabolic parameters.

There were no group differences in any metabolic parameter depending if patients were receiving an antidepressant treatment at baseline. However, a statistical significant higher proportion of patients who were under antidepressant treatment in the 2-year follow up visit presented a body weight gain $>7 \%$ ( 81,3 vs. $54,7 \%, \chi 2=3.94, p=0.047$, phi=0.19), overweight criteria $(62,5$ vs. $30,2 \%, \chi 2=7.99, p=0.018)$ and MetS $(41,2$ vs. $9,2 \%, \chi 2=10.31, p=0.001$, phi $=-0.35)$ and higher mean systolic pressure blood levels (126.12 vs. $118.41 \mathrm{mmHg}, t=2.28, p=0.024)$. 
The subgroup of patients receiving mood stabilizers at baseline (46/335: 13.7\%) presented higher basal mean levels of triglycerides ( 102.21 vs. $86.07 \mathrm{mg} / \mathrm{dL}, \mathrm{t}=2.09, \mathrm{p}=0.038$ ), which kept being the only significant difference in two-year follow up visit (144.45 vs. $103.58 \mathrm{mg} / \mathrm{dL}, \mathrm{t}=2.16, \mathrm{p}=0.033$ ).

\section{Discussion}

These results highlight the extremely high risk of patients at early phases of schizophrenia and other psychotic disorders of developing CVD risk factors and the rapid worsening of the metabolic profile during two years period. From the beginning of the study, the FEP group showed differences in metabolic parameters compared to the control group (table 1). After two years of follow-up, the metabolic status of the FEP group clearly worsened compared to the control group in almost all metabolic measures (figure 1, table 2), with higher rates of overweight/obesity and MetS.

The baseline findings support the existence of underlying predisposition of FEP patients to present such alterations from the very beginning of the disorder or even before starting the psychopharmacological treatment (Fernandez-Egea et al., 2009; Verma et al., 2009; Zhai et al., 2016).

The results in the follow-up are in the line of previous works, showing how first months of treatment are critical in terms of body weight gain and metabolic syndrome rates (Fleischhacker et al., 2013; Patel et al., 2009; Perez-Iglesias et al., 2014; Tek et al., 2016). Indeed, we observed a quick increase of body weight gain and waist circumference during the first year with a subsequent stabilization afterwards. Our results summarize in the same cohort, MetS differences found in meta-analysis between naïve patients (Vancampfort et al., 2013) and FEP (Mitchell et al., 2013) as a continuum in the rate of increasing risk over time.

By genders, both subgroups of patients showed a similar metabolic deterioration during the two year follow-up after a FEP, but the male group started from a worse metabolic profile in certain measures (Figure 1), similarly to previous results reported from the CAFE Study in the US (Patel et al., 2009).

The affective psychoses subgroup presented higher rates of MetS at the end of the follow-up, possibly mediated by the coadjuvant use of antidepressant and mood stabilizers, more frequent in this subgroup (Bioque et al., 2016). A higher proportion of patients who were under antidepressant treatment in the 2-year follow up visit presented relevant body weight gain, overweight and MetS, together with higher systolic pressure blood levels, while those receiving mood stabilizers higher mean levels of triglycerides. The relatively low number of subjects in this subgroup of affective psychosis $(n=55)$ is another factor to consider when interpreting these results.

A key feature of this study is that the age of inclusion is wider than in other previous works. Globally, the subgroup of early onset showed a pattern of metabolic worsening similar with the adult subpopulation, being a consistent finding with previous studies (Correll et al., 2009). However, the early onset was associated with a greater worsening in the glucose metabolism. This vulnerability should be considered when treating this population and in guidelines design (Galling and Correll, 2015).

Another aim of this study was to determine the effect of psychopharmacological treatment on the metabolic profile in a real-world setting. Those patients who were not receiving antipsychotic treatment at baseline showed significant lower rates of diabetes, together with lower waist circumference, glucose and LDL cholesterol levels, in the line of previous findings reported in the literature with antipsychoticnaïve populations (Fernandez-Egea et al., 2009; Greenhalgh et al., 2016; Perry et al., 2016; Pillinger et al., 2017; Verma et al., 2009). 
One point in which we have focused our study is in the effects of antipsychotic polytherapy, which is a common practice in everyday clinical practice (Bernardo et al., 2012; Tani et al., 2013). Polytherapy regimens at the beginning of the study were associated to higher body weight, BMI, glucose and glycated hemoglobin levels. Besides, the baseline daily dose of antipsychotic correlated with the body weight.

Some limitations should be taken into account when analyzing these results. Firstly, patients could be under antipsychotic treatment for a maximum of 12 months at the study baseline, as the inclusion/exclusion criteria allowed to include subjects diagnosed of a FEP in the previous year. Although only a small proportion of the sample $(n=49,14.6 \%)$ had been taking antipsychotics for more than three months before the inclusion, the number of days of the antipsychotic treatment previous to the baseline assessment was used a covariate in that analysis, as we found positive correlations between the length of previous antipsychotic treatment and some of the metabolic measures. Secondly, the PEPs project was a naturalistic study, not a randomized controlled trial, so patients could be changing treatments during the follow-up period according to the clinician's choice; Thirdly, the major part of the participant sites are tertiary care centers linked to the Spanish network of translational research (CIBERSAM), so patient samples and therapeutic strategies may differ from those used in other areas; Fourthly, the relatively high number of drop-out during the follow-up period $(40.9 \%$ of the cases and $37.6 \% \%$ of the controls) may have limited the capability to detect differences between groups at the end of the study. Finally, another aspect that should be taken into account when interpreting these results is that the proportion of patients with an early onset included in our study (17\%, 57/335) was higher compared to other similar studies made in subjects with a FEP in Australia $(11.2 \%, 41 / 366)$ or with schizophrenia in Finland (4.7\%, 19/400) (Amminger et al., 2011; Cannon et al., 1999).

A strength of this study is that that the diagnostic evaluation was performed with a very comprehensive protocol, with strict inclusion-exclusion criteria, with a wide age of inclusion better reflecting the natural history of the disorders, making this sample much closer to the "real life" FEP population (Bernardo et al., 2013). To our knowledge, there are no previous similar studies with this broad range of age and including patients with criteria which might be excluded in other ones (suicide ideation, drug use). Besides, the Spanish public health system universal coverage suggests that the population studied gives a good perspective of what is presently the clinical practice in this country (Bioque et al., 2016).

These findings may help clinicians to detect subgroups of patients with an incremented risk to develop certain cardiovascular comorbidities according to accessible clinical variables such as gender, diagnosis or age of onset. Besides, the torpid evolution of the major part of the metabolic measures during the follow-up visits, with higher rates of overweight/obesity and MetS, highlights the importance of an adequate clinical management (both for mental illness and metabolic comorbidities) in this population. These results indicate the need for and can help guide primary and secondary prevention strategies for metabolic risk factors in early phases of psychotic disorders.

Figure 1 Title: Evolution of BMI, body weight, waist circumference, glycated hemoglobin, triglycerides, high density lipoprotein (HDL) cholesterol and total cholesterol in male and female patients during the two-year follow-up period. 


\section{References}

Alberti, K.G.M.M., Zimmet, P., Shaw, J., 2005. The metabolic syndrome - a new worldwide definition. The Lancet 366(9491), 1059-1062.

American Psychiatric Association (Washington), 1994. DSM-IV: diagnostic and statistical manual of mental disorders, 4th ed. American Psychiatric Association, Washington, DC.

Amminger, G.P., Henry, L.P., Harrigan, S.M., Harris, M.G., Alvarez-Jimenez, M., Herrman, H., Jackson, H.J., McGorry, P.D., 2011. Outcome in early-onset schizophrenia revisited: Findings from the Early Psychosis Prevention and Intervention Centre long-term follow-up study. Schizophrenia research 131(1â€"3), 112-119.

Anto, P.R., Henriette Thisted, H., Theresa, W., Dan, C., Ole, M., Anders, D.B.r., Christiane, G., 2017. Endogenous and Antipsychotic-Related Risks for Diabetes Mellitus in Young People With Schizophrenia: A Danish Population-Based Cohort Study. American Journal of Psychiatry 0(0), appi.ajp.2016.16040442.

Arango, C., Bobes, J., Aranda, P., Carmena, R., Garcia-Garcia, M., Rejas, J., 2008. A comparison of schizophrenia outpatients treated with antipsychotics with and without metabolic syndrome: findings from the CLAMORS study. Schizophr Res 104(1-3), 1-12.

Bernardo, M., Bioque, M., 2014. What have we learned from research into first-episode psychosis? Rev Psiquiatr Salud Ment 7(2), 61-63.

Bernardo, M., Bioque, M., Cabrera, B., Lobo, A., Gonzalez-Pinto, A., Pina, L., Corripio, I., Sanjuan, J., Mane, A., Castro-Fornieles, J., Vieta, E., Arango, C., Mezquida, G., Gasso, P., Parellada, M., Saiz-Ruiz, J., Cuesta, M.J., Mas, S., 2017. Modelling gene-environment interaction in first episodes of psychosis. Schizophr Res.

Bernardo, M., Bioque, M., Parellada, M., Saiz Ruiz, J., Cuesta, M.J., Llerena, A., Sanjuan, J., Castro-Fornieles, J., Arango, C., Cabrera, B., 2013. Assessing clinical and functional outcomes in a gene-environment interaction study in first episode of psychosis (PEPs). Rev Psiquiatr Salud Ment 6(1), 4-16.

Bernardo, M., Coma, A., Ibanez, C., Zara, C., Bari, J.M., Serrano-Blanco, A., 2012. Antipsychotic polypharmacy in a regional health service: a population-based study. BMC Psychiatry 12, 42.

Bioque, M., Llerena, A., Cabrera, B., Mezquida, G., Lobo, A., Gonzalez-Pinto, A., Diaz-Caneja, C.M., Corripio, I., Aguilar, E.J., Bulbena, A., Castro-Fornieles, J., Vieta, E., Lafuente, A., Mas, S., Parellada, M., Saiz-Ruiz, J., Cuesta, M.J., Bernardo, M., 2016. A Pharmacovigilance Study in First Episode of Psychosis: Psychopharmacological Interventions and Safety Profiles in the PEPs Project. Int J Neuropsychopharmacol 19(4).

Cannon, M., Jones, P., Huttunen, M.O., et al., 1999. School performance in finnish children and later development of schizophrenia: A population-based longitudinal study. Archives of General Psychiatry 56(5), 457-463.

Cohen, J., 1988. Statistical Power Analysis for the Behavioral Sciences (Revised Edition), 2nd ed. Laurence Erlbaum Associates, Hillsdale, NJ.

Correll, C.U., Manu, P., Olshanskiy, V., Napolitano, B., Kane, J.M., Malhotra, A.K., 2009. Cardiometabolic risk of second-generation antipsychotic medications during first-time use in children and adolescents. JAMA 302(16), 1765-1773.

Fernandez-Egea, E., Bernardo, M., Donner, T., Conget, I., Parellada, E., Justicia, A., Esmatjes, E., Garcia-Rizo, C., Kirkpatrick, B., 2009. Metabolic profile of antipsychotic-naive individuals with non-affective psychosis. The British Journal of Psychiatry 194(5), 434-438.

Fernandez-Egea, E., Miller, B., Garcia-Rizo, C., Bernardo, M., Kirkpatrick, B., 2011. Metabolic effects of olanzapine in patients with newly diagnosed psychosis. Journal of clinical psychopharmacology 31(2), 154-159.

First, M., Spitzer, R., Gibbon, M., Williams, J., 1994. Structured Clinical Interview for DSM-IV Axis I Disorders - Administration Booklet. American Psychiatric Press Inc., Washington, DC. 
First, M., Spitzer, R., Gibbon, M., Williams, J., 1999. SCID-II: guía del usuario para la entrevista clínica estructurada para los trastornos de la personalidad. Masson, Barcelona.

Fleischhacker, W.W., Siu, C.O., Boden, R., Pappadopulos, E., Karayal, O.N., Kahn, R.S., 2013. Metabolic risk factors in first-episode schizophrenia: baseline prevalence and course analysed from the European First-Episode Schizophrenia Trial. Int J Neuropsychopharmacol 16(5), 987995.

Galling, B., Correll, C.U., 2015. Do antipsychotics increase diabetes risk in children and adolescents? Expert Opinion on Drug Safety 14(2), 219-241.

Garcia-Rizo, C., Fernandez-Egea, E., Oliveira, C., Meseguer, A., Cabrera, B., Mezquida, G., Bioque, M., Penades, R., Parellada, E., Bernardo, M., Kirkpatrick, B., 2017. Metabolic syndrome or glucose challenge in first episode of psychosis? Eur Psychiatry 41, 42-46.

Garcia-Rizo, C., Kirkpatrick, B., Fernandez-Egea, E., Oliveira, C., Bernardo, M., 2016. Abnormal glycemic homeostasis at the onset of serious mental illnesses: A common pathway. Psychoneuroendocrinology 67, 70-75.

Greenhalgh, A.M., Gonzalez-Blanco, L., Garcia-Rizo, C., Fernandez-Egea, E., Miller, B., Arroyo, M.B., Kirkpatrick, B., 2016. Meta-analysis of glucose tolerance, insulin, and insulin resistance in antipsychotic-naive patients with nonaffective psychosis. Schizophr Res 179, 57-63.

Kaufman, J., Birmaher, B., Brent, D., Rao, U., Flynn, C., Moreci, P., Williamson, D., Ryan, N., 1997. Schedule for Affective Disorders and Schizophrenia for School-Age Children-Present and Lifetime Version (K-SADS-PL): initial reliability and validity data. J Am Acad Child Adolesc Psychiatry 36(7), 980-988.

Keinanen, J., Mantere, O., Kieseppa, T., Mantyla, T., Torniainen, M., Lindgren, M., Sundvall, J., Suvisaari, J., 2015. Early insulin resistance predicts weight gain and waist circumference increase in first-episode psychosis--A one year follow-up study. Schizophr Res 169(1-3), 458463.

Kirkpatrick, B., Garcia-Rizo, C., Tang, K., Fernandez-Egea, E., Bernardo, M., 2010. Cholesterol and triglycerides in antipsychotic-naive patients with nonaffective psychosis. Psychiatry Res 178(3), 559-561.

Laursen, T.M., Wahlbeck, K., Hallgren, J., Westman, J., Osby, U., Alinaghizadeh, H., Gissler, M., Nordentoft, M., 2013. Life expectancy and death by diseases of the circulatory system in patients with bipolar disorder or schizophrenia in the Nordic countries. PloS one 8(6), e67133.

Misiak, B., Stańczykiewicz, B., Łaczmański, Ł., Frydecka, D., 2017. Lipid profile disturbances in antipsychotic-naive patients with first-episode non-affective psychosis: A systematic review and meta-analysis. Schizophrenia research.

Mitchell, A.J., Vancampfort, D., De Herdt, A., Yu, W., De Hert, M., 2013. Is the Prevalence of Metabolic Syndrome and Metabolic Abnormalities Increased in Early Schizophrenia? A Comparative Meta-Analysis of First Episode, Untreated and Treated Patients. Schizophrenia Bulletin 39(2), 295-305.

Mitchell, A.J., Vancampfort, D., Sweers, K., van Winkel, R., Yu, W., De Hert, M., 2011. Prevalence of metabolic syndrome and metabolic abnormalities in schizophrenia and related disorders--a systematic review and meta-analysis. Schizophr Bull 39(2), 306-318.

Nordentoft, M., Wahlbeck, K., Hallgren, J., Westman, J., Osby, U., Alinaghizadeh, H., Gissler, M., Laursen, T.M., 2013. Excess mortality, causes of death and life expectancy in 270,770 patients with recent onset of mental disorders in Denmark, Finland and Sweden. PloS one 8(1), e55176.

Patel, J.K., Buckley, P.F., Woolson, S., Hamer, R.M., McEvoy, J.P., Perkins, D.O., Lieberman, J.A., 2009. Metabolic profiles of second-generation antipsychotics in early psychosis: findings from the CAFE study. Schizophr Res 111(1-3), 9-16.

Perez-Iglesias, R., Martinez-Garcia, O., Pardo-Garcia, G., Amado, J.A., Garcia-Unzueta, M.T., Tabares-Seisdedos, R., Crespo-Facorro, B., 2014. Course of weight gain and metabolic abnormalities in first treated episode of psychosis: the first year is a critical period for development of cardiovascular risk factors. Int J Neuropsychopharmacol 17(1), 41-51. 
Perkins, D.O., Leserman, J., Jarskog, L.F., Graham, K., Kazmer, J., Lieberman, J.A., 2000. Characterizing and dating the onset of symptoms in psychotic illness: the Symptom Onset in Schizophrenia (SOS) inventory. Schizophr Res 44(1), 1-10.

Perry, B.I., McIntosh, G., Weich, S., Singh, S., Rees, K., 2016. The association between firstepisode psychosis and abnormal glycaemic control: systematic review and meta-analysis. Lancet Psychiatry 3(11), 1049-1058.

Pillinger, T., Beck, K., Gobjila, C., Donocik, J.G., Jauhar, S., Howes, O.D., 2017. Impaired Glucose Homeostasis in First-Episode Schizophrenia: A Systematic Review and Meta-analysis. JAMA Psychiatry 74(3), 261-269.

Ryan, M.C., Collins, P., Thakore, J.H., 2003. Impaired fasting glucose tolerance in first-episode, drug-naive patients with schizophrenia. Am J Psychiatry 160(2), 284-289.

Ryan, M.C., Flanagan, S., Kinsella, U., Keeling, F., Thakore, J.H., 2004. The effects of atypical antipsychotics on visceral fat distribution in first episode, drug-naive patients with schizophrenia. Life Sci 74(16), 1999-2008.

Spelman, L.M., Walsh, P.I., Sharifi, N., Collins, P., Thakore, J.H., 2007. Impaired glucose tolerance in first-episode drug-naive patients with schizophrenia. Diabet Med 24(5), 481-485.

Tani, H., Uchida, H., Suzuki, T., Fujii, Y., Mimura, M., 2013. Interventions to reduce antipsychotic polypharmacy: A systematic review. Schizophrenia Research 143(1), 215-220.

Tek, C., Kucukgoncu, S., Guloksuz, S., Woods, S.W., Srihari, V.H., Annamalai, A., 2016. Antipsychotic-induced weight gain in first-episode psychosis patients: a meta-analysis of differential effects of antipsychotic medications. Early Interv Psychiatry 10(3), 193-202.

Vancampfort, D., Wampers, M., Mitchell, A.J., Correll, C.U., De Herdt, A., Probst, M., De Hert, M., 2013. A meta-analysis of cardio-metabolic abnormalities in drug naive, first-episode and multi-episode patients with schizophrenia versus general population controls. World Psychiatry 12(3), 240-250.

Verma, S.K., Subramaniam, M., Liew, A., Poon, L.Y., 2009. Metabolic risk factors in drug-naive patients with first-episode psychosis. J Clin Psychiatry 70(7), 997-1000.

Zhai, D., Cui, T., Xu, Y., Feng, Y., Wang, X., Yang, Y., Li, S., Zhou, D., Dong, G., Zhao, Y., Zhang, R., 2016. Cardiometabolic risk in first-episode schizophrenia (FES) patients with the earliest stages of both illness and antipsychotic treatment. Schizophr Res.

Zimmet, P., Alberti, K.G.M.M., Kaufman, F., Tajima, N., Silink, M., Arslanian, S., Wong, G., Bennett, P., Shaw, J., Caprio, S., Group, I.D.F.C., 2007. The metabolic syndrome in children and adolescents - an IDF consensus report. Pediatric Diabetes 8(5), 299-306. 
Table 1. Demographic and clinical characteristics and baseline metabolic measures.

\begin{tabular}{|c|c|c|c|c|}
\hline & $\begin{array}{l}\text { First Episode Psychosis } \\
\qquad(n=335)\end{array}$ & $\begin{array}{l}\text { Control } \\
(n=253)\end{array}$ & Statistic & P-value \\
\hline $\begin{array}{l}\text { Age - years [mean }(\mathrm{sd})] \\
\text { Subjects }<18 \text { years old }- \text { no. (\%) }\end{array}$ & $\begin{array}{l}23.6(6) \\
57(17)\end{array}$ & $\begin{array}{l}24.2(6.4) \\
32(12.6)\end{array}$ & $\begin{array}{l}t=-1.26 \\
\chi^{2}=2.14\end{array}$ & $\begin{array}{l}0.21 \\
0.16\end{array}$ \\
\hline $\begin{array}{c}\text { Gender }- \text { no. }(\%) \\
\text { Female } \\
\text { Male } \\
\end{array}$ & $\begin{array}{l}110(32.8 \%) \\
225(67.2 \%)\end{array}$ & $\begin{array}{c}91(36 \%) \\
162(64 \%)\end{array}$ & $\chi^{2}=0.63$ & 0.43 \\
\hline $\begin{array}{l}\text { Ethnic Group - no. (\%) } \\
\text { Caucasian } \\
\text { Gipsy } \\
\text { Maghrebian } \\
\text { Sub-Saharan } \\
\text { Asian } \\
\text { Caribbean } \\
\text { Hispanic } \\
\text { Other } \\
\end{array}$ & $\begin{array}{c}284(84.8 \%) \\
6(1.8 \%) \\
8(2.4 \%) \\
4(1.2 \%) \\
4(1.2 \%) \\
8(2.4 \%) \\
17(5.1 \%) \\
4(1.2 \%) \\
\end{array}$ & $\begin{array}{c}228(90.1 \%) \\
0(0) \\
2(0.8 \%) \\
0(0) \\
1(0.4 \%) \\
4(1.6 \%) \\
14(5.5 \%) \\
4(1.6 \%) \\
\end{array}$ & $x^{2}=11.95$ & 0.11 \\
\hline $\begin{array}{l}\text { Metabolic measures - mean (sd) } \\
\text { Glucose (mg/dL) } \\
\text { Glycated hemoglobin (\%) } \\
\text { Triglycerides }(\mathrm{mg} / \mathrm{dL}) \\
\text { Total Cholesterol }(\mathrm{mg} / \mathrm{dL}) \\
\text { HDL Cholesterol }(\mathrm{mg} / \mathrm{dL}) \\
\text { LDL Cholesterol }(\mathrm{mg} / \mathrm{dL}) \\
\text { Body weight }(\mathrm{Kg}) \\
\text { BMI }\left(\mathrm{kg} / \mathrm{m}^{2}\right) \\
\text { Abdominal circumference }(\mathrm{cm}) \\
\text { Systolic blood pressure }(\mathrm{mmHg}) \\
\text { Diastolic blood pressure }(\mathrm{mmHg})\end{array}$ & $\begin{array}{c}84.9(16.2) \\
5.2(0.5) \\
88.4(47.7) \\
161.9(36.5) \\
49.4(12.7) \\
95.5(28.9) \\
68.9(14.1) \\
23.5(4.2) \\
85.7(11.5) \\
119.9(13.3) \\
71.9(10.1) \\
\end{array}$ & $\begin{array}{c}83.7(10.5) \\
5.2(0.5) \\
80.9(41.7) \\
169.6(37.9) \\
55(13.8) \\
98.1(33.1) \\
69.1(12.7) \\
23.5(3.4) \\
84.8(9.5) \\
119.8(14.8) \\
69.9(9.6) \\
\end{array}$ & $\begin{array}{l}F=0.082 \\
F=1.365 \\
F=0.067 \\
F=8.381 \\
F=6.410 \\
F=5.452 \\
F=1.439 \\
F=1.577 \\
F=0.037 \\
F=0.139 \\
F=0.748\end{array}$ & $\begin{array}{c}0.775 \\
0.243 \\
0.795 \\
0.004 * \\
0.012 * \\
0.020 * \\
0.231 \\
0.210 \\
0.848 \\
0.710 \\
0.388 \\
\end{array}$ \\
\hline $\begin{array}{l}\text { IDF Metabolic Syndrome criteria - \% (no.) } \\
\text { Abdominal obesity } \\
\text { Glucose } \\
\text { Triglycerides } \\
\text { HDL Cholesterol } \\
\text { Blood Pressure }\end{array}$ & $\begin{array}{l}6.6 \%(13 / 197) \\
34 \%(88 / 259) \\
5.5 \%(17 / 309) \\
7.5 \%(23 / 306) \\
30.6 \%(81 / 265) \\
23.6 \%(74 / 314)\end{array}$ & $\begin{array}{c}3.8 \%(7 / 184) \\
42.9 \%(66 / 213) \\
0.9 \%(2 / 226) \\
6.2 \%(14 / 225) \\
15.7 \%(34 / 216) \\
25.8 \%(59 / 229)\end{array}$ & $\begin{array}{c}F=0.361 \\
F=0.839 \\
F=3.945 \\
F=0.11 \\
F=10.155 \\
F=0.141\end{array}$ & $\begin{array}{c}0.55 \\
0.36 \\
0.048^{*} \\
0.74 \\
0.002^{*} \\
0.71 \\
\end{array}$ \\
\hline $\begin{array}{l}\text { Overweight - \% (no.) } \\
\text { Obesity - \% (no.) }\end{array}$ & $\begin{array}{c}23.1 \%(75 / 324) \\
8 \%(26 / 324) \\
\end{array}$ & $\begin{array}{c}19.8 \%(48 / 243) \\
6.6 \%(16 / 243) \\
\end{array}$ & $\begin{array}{c}F=0.4 \\
F=0.113\end{array}$ & $\begin{array}{l}0.53 \\
0.74 \\
\end{array}$ \\
\hline Diabetes - \% (no.) & $0.64 \%(2 / 309)$ & $0.44 \%(1 / 226)$ & $F=0.324$ & 0.57 \\
\hline
\end{tabular}

Abbreviations: BMI, body mass index; HDL, High-Density Lipoprotein; IDF, International Diabetes Federation criteria; LDL, Low-Density Lipoprotein.

${ }^{*} p<0.05 .{ }^{a}$ Affective psychosis includes DSM-IV diagnosis of unipolar depression or bipolar disorder with psychotic features and schizoaffective disorder. 
Table 2. Anthropometric, vital signs and metabolic measures comparison between the patients and healthy controls groups at the two year follow-up visit.

\begin{tabular}{|c|c|c|c|c|}
\hline & $\begin{array}{c}\text { First Episode Psychosis } \\
\text { (n=198) }\end{array}$ & $\begin{array}{c}\text { Control } \\
\text { (n=158) }\end{array}$ & Statistic & p-value \\
\hline Metabolic measures - mean (sd) & & & & \\
Glucose (mg/dL) & $86.4(10.7)$ & $83.1(11.9)$ & $\mathrm{F}=7.45$ & $0.006^{*}$ \\
Glycated hemoglobin (\%) & $5.3(0.9)$ & $5.2(0.4)$ & $\mathrm{F}=1.27$ & 0.26 \\
Triglycerides (mg/dL) & $108.1(80.3)$ & $82.3(52.6)$ & $\mathrm{F}=10.86$ & $0.001^{*}$ \\
Total Cholesterol (mg/dL) & $170.8(35.2)$ & $170.6(33.9)$ & $\mathrm{F}=3.08$ & 0.79 \\
HDL Cholesterol (mg/dL) & $47.6(13.5)$ & $54.5(14.8)$ & $\mathrm{F}=40.48$ & $<0.001^{*}$ \\
LDL Cholesterol (mg/dL) & $103.2(29.0)$ & $100.1(28.4)$ & $\mathrm{F}=0.002$ & 0.96 \\
Body weight (Kg) & $76.6(15.9)$ & $69.6(12.9)$ & $\mathrm{F}=5.14$ & $0.024^{*}$ \\
BMI & $26.1(4.8)$ & $23.7(3.2)$ & $\mathrm{F}=7.94$ & $0.005^{*}$ \\
Abdominal circumference (cm) & $90.8(12.8)$ & $84.2(9.3)$ & $\mathrm{F}=14.46$ & $<0.001^{*}$ \\
Systolic blood pressure (mmHg) & $120.8(14.1)$ & $118.8(12.9)$ & $\mathrm{F}=0.74$ & 0.39 \\
Diastolic blood pressure (mmHg) & $71.2(10.3)$ & $69.1(9.2)$ & $\mathrm{F}=8.57$ & $0.004^{*}$ \\
\hline IDF Abdominal obesity & $14.6 \%(22 / 151)$ & $3.4 \%(4 / 118)$ & $\chi^{2}=9.48$ & $0.001^{*}$ \\
IDF Glucose & $48.3 \%(86 / 178)$ & $26.2 \%(34 / 130)$ & $\chi^{2}=15.52$ & $<0.001^{*}$ \\
IDF Triglycerides & $8.6 \%(17 / 198)$ & $3.2 \%(5 / 157)$ & $\chi^{2}=4.39$ & $0.045^{*}$ \\
IDF HDL Cholesterol & $18.4 \%(36 / 196)$ & $7.6 \%(12 / 158)$ & $\chi^{2}=8.66$ & $0.002^{*}$ \\
IDF Blood Pressure & $34.7 \%(60 / 173)$ & $18.4 \%(28 / 152)$ & $\chi^{2}=10.84$ & $0.001^{*}$ \\
\hline Metabolic Syndrome - \% (no.) & $25.8 \%(49 / 190)$ & $21.9 \%(30 / 137)$ & $\chi^{2}=0.66$ & 0.44 \\
\hline Overweight - \% (no.) & $33 \%(63 / 191)$ & $24.6 \%(34 / 138)$ & $\chi^{2}=25.43$ & $<0.001^{*}$ \\
Obesity - \% (no.) & $20.4 \%(39 / 191)$ & $4.3 \%(6 / 138)$ & \\
\hline Diabetes - \% (no.) & $0.5 \%(1 / 198)$ & $0.6 \%(1 / 157)$ & $\chi^{2}=0.027$ & 0.99 \\
\hline
\end{tabular}

Abbreviations: BMI, body mass index; HDL, High-Density Lipoprotein; IDF, International Diabetes Federation criteria; LDL, Low-Density Lipoprotein. $* \mathrm{p}<0.05$. 


\begin{tabular}{|c|c|c|c|c|c|c|c|c|}
\hline $\begin{array}{l}\text { Anthropometric, vital signs and } \\
\text { metabolic mean measures - mean } \\
\text { (sd) }\end{array}$ & $\begin{array}{l}\text { Baseline } \\
(n=335)\end{array}$ & $\begin{array}{c}\text { 2-months } \\
(n=283)\end{array}$ & $\begin{array}{c}\text { 6-months } \\
(n=260)\end{array}$ & $\begin{array}{c}\text { 12-months } \\
(n=237)\end{array}$ & $\begin{array}{c}\text { 24-months } \\
(n=198)\end{array}$ & Statistics & p-value & $\begin{array}{l}\text { Partial } \\
\text { eta } \\
\text { Squared* }\end{array}$ \\
\hline Glucose $(\mathrm{mg} / \mathrm{dL})$ & $84.9(16.2)$ & $87.1(16.2)$ & $87.1(18.2)$ & $87.2(13.1)$ & $86.4(10.7)$ & $W L=0.95, F=1.79$ & 0.134 & 0.51 \\
\hline Glycated hemoglobin (\%) & $5.2(0.5)$ & $5.2(0.4)$ & $5.2(0.4)$ & $5.3(0.5)$ & $5.3(0.9)$ & $W L=0.77, F=8.13$ & $<0.001$ & 0.23 \\
\hline Triglycerides (mg/dL) & $88.4(47.7)$ & $101.9(62.1)$ & $107.2(67.4)$ & $100.6(86.6)$ & $108.1(80.3)$ & $W L=0.92, F=2.88$ & 0.025 & 0.08 \\
\hline Total Cholesterol (mg/dL) & $161.9(36.5)$ & $169.3(35.9)$ & $169.1(35.6)$ & $164.4(34.9)$ & $170.8(35.2)$ & $W L=0.88, F=4.84$ & 0.001 & 0.12 \\
\hline HDL Cholesterol (mg/dL) & $49.4(12.7)$ & $48.4(12.4)$ & $47.8(12.9)$ & $45.6(11.6)$ & $47.6(13.5)$ & $W L=0.87, F=4.18$ & 0.003 & 0.13 \\
\hline LDL Cholesterol (mg/dL) & $95.5(28.9)$ & $100.5(30.9)$ & $100.5(31.5)$ & $100.9(28.3)$ & $103.2(29.0)$ & $W L=0.93, F=1.97$ & 0.104 & 0.07 \\
\hline Body weight (Kg) & $68.9(14.1)$ & $72.1(13.5)$ & $74.4(14.6)$ & $76.4(15.5)$ & $76.6(15.9)$ & $W L=0.57, F=27.37$ & $<0.001$ & 0.43 \\
\hline BMI $\left(\mathrm{kg} / \mathrm{m}^{2}\right)$ & $23.5(4.2)$ & $24.5(3.8)$ & $25.3(4.1)$ & $25.9(4.6)$ & $26.1(4.8)$ & $W L=0.57, F=28.57$ & $<0.001$ & 0.44 \\
\hline Abdominal circumference $(\mathrm{cm})$ & $85.7(11.5)$ & $88.1(11.4)$ & $90.7(11.6)$ & $90.8(12.2)$ & $90.8(12.8)$ & $W L=0.69, F=12.88$ & $<0.001$ & 0.30 \\
\hline Systolic blood pressure (mmHg) & $119.9(13.3)$ & $119.8(15.3)$ & $119.5(13.6)$ & $120.2(13.1)$ & $120.8(14.1)$ & $W L=0.98, F=0.66$ & 0.62 & 0.019 \\
\hline Diastolic blood pressure $(\mathrm{mmHg})$ & $71.9(10.1)$ & $70.6(10.3)$ & $70.8(9.6)$ & $71.5(9.7)$ & $71.2(10.3)$ & $W L=0.94, F=2.04$ & 0.092 & 0.057 \\
\hline Metabolic Syndrome - \% (no.) & $6.6 \%(13 / 197)$ & $11.4 \%(21 / 185)$ & $14.6 \%(29 / 198)$ & $14.6 \%(26 / 178)$ & $14.6 \%(22 / 151)$ & $C Q=6.00$ & 0.20 & - \\
\hline Overweight - \% (no.) & $23.1 \%(75 / 324)$ & $26.5 \%(74 / 279)$ & $39.7 \%(102 / 257)$ & $36.8 \%(85 / 231)$ & $33 \%(63 / 191)$ & $C Q=13.85$ & 0.008 & - \\
\hline Obesity - \% (no.) & $8 \%(26 / 324)$ & $12.2 \%(34 / 279)$ & $13.2 \%(34 / 257)$ & $19 \%(44 / 231)$ & $20.4 \%(39 / 191)$ & $C Q=33.77$ & $<0.001$ & - \\
\hline Diabetes - \% (no.) & $0.6 \%(2 / 309)$ & $0.8 \%(2 / 255)$ & $2.4 \%(6 / 249)$ & $0.9 \%(2 / 220)$ & $0.5 \%(1 / 198)$ & $C Q=4.00$ & 0.41 & - \\
\hline
\end{tabular}

CQ: Cochran's Q; WL: Wilk's Lambda. *Partial Eta Squared value of effect size (0.01-0.05=small, 0.06-1.3=moderate, $>0.14=$ large). 
Table 4. Psychopharmacological treatment in the baseline and in the two year follow-up visit.

\begin{tabular}{|c|c|c|}
\hline & Baseline & 2-year follow-up visit \\
\hline Subjects Antipsychotic treatment & & \\
No antipsychotics & $31 / 335(9.2 \%)$ & $20 / 116(17.2 \%)$ \\
Antipsychotic Monotherapy & $231 / 335(69 \%)$ & $84 / 116(72.4 \%)$ \\
Antipsychotic Polytherapy & $73 / 335(21.8 \%)$ & $12 / 116(10.4 \%)$ \\
\hline Route of antipsychotic & & \\
Only oral & $288 / 304(94.7)$ & $86 / 96(89.6 \%)$ \\
Only Long Acting Injection & $1 / 304(0.3)$ & $9 / 96(9.4 \%)$ \\
Both & $15 / 304(4.9)$ & $1 / 96(1 \%)$ \\
\hline Chlorpromazine equivalent mean dose & $599.08( \pm 442.56)$ & $345.02( \pm 292.79)$ \\
\hline Subjects with other treatments & & \\
Anticholinergics & $41 / 335(12.2 \%)$ & $5 / 116(4.3 \%)$ \\
Antidepressants & $41 / 335(12.2 \%)$ & $18 / 116(15.5 \%)$ \\
Mood stabilizers & $46 / 335(13.7 \%)$ & $30 / 116(25.9 \%)$ \\
Benzodiazepines & $130 / 335(38.8 \%)$ & $18 / 116(15.5 \%)$ \\
\hline
\end{tabular}


A

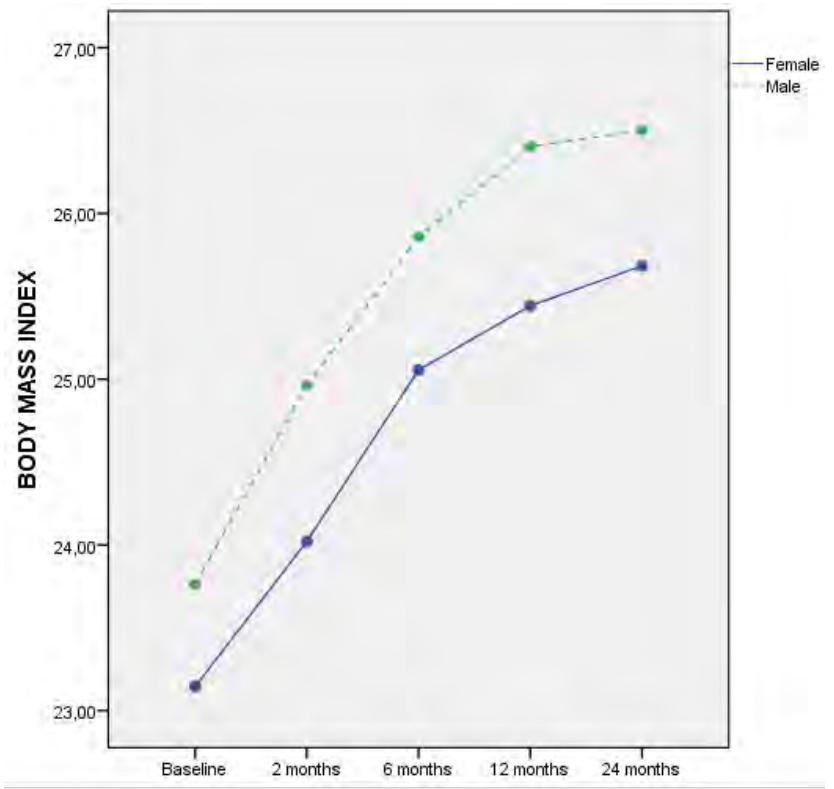

C

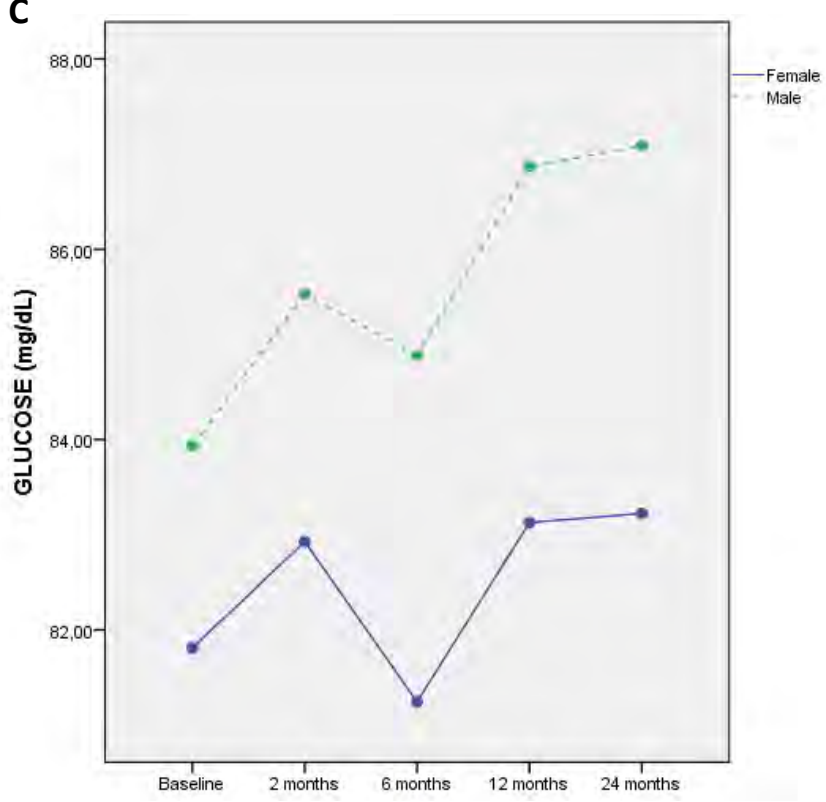

E

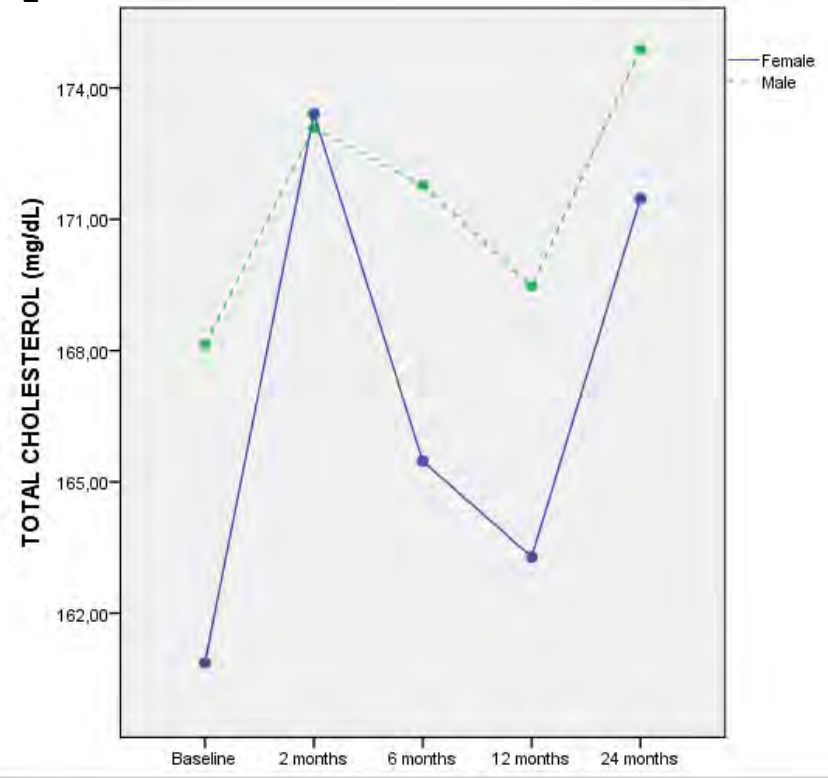

B

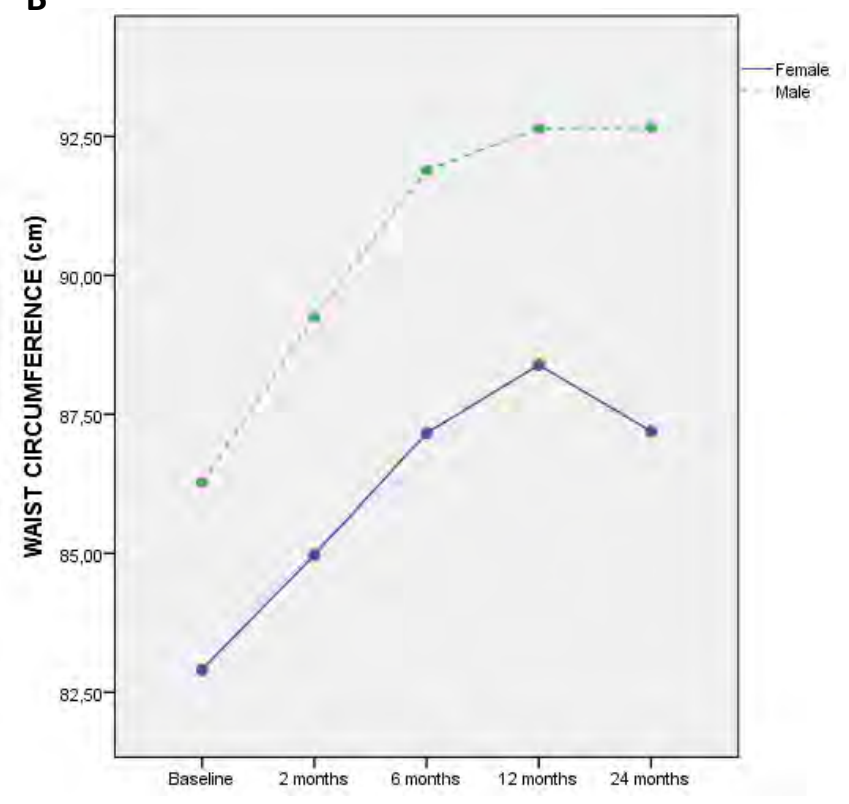

D

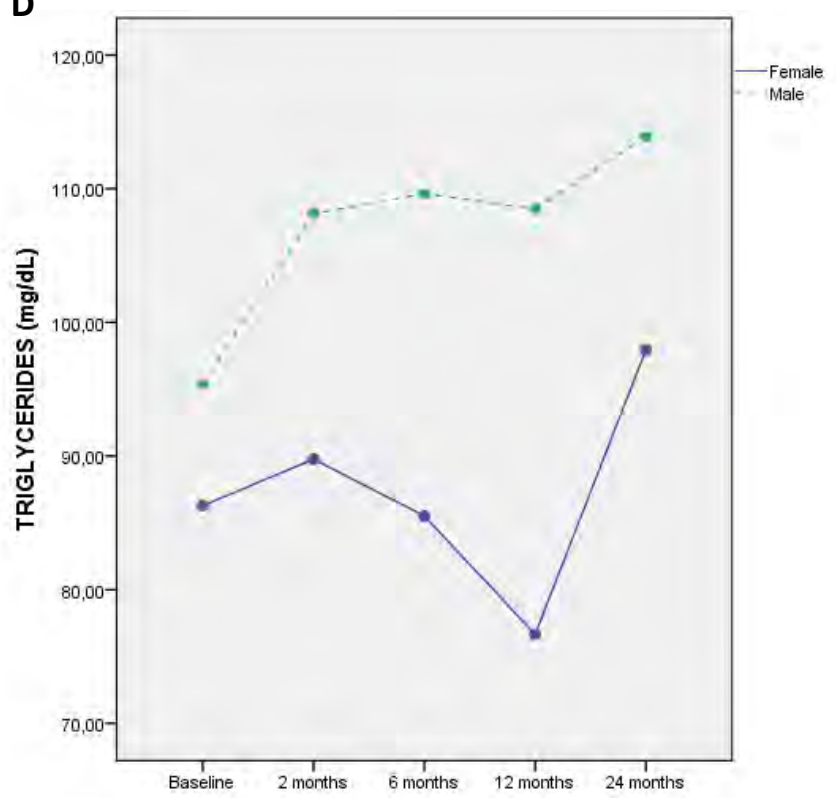

F

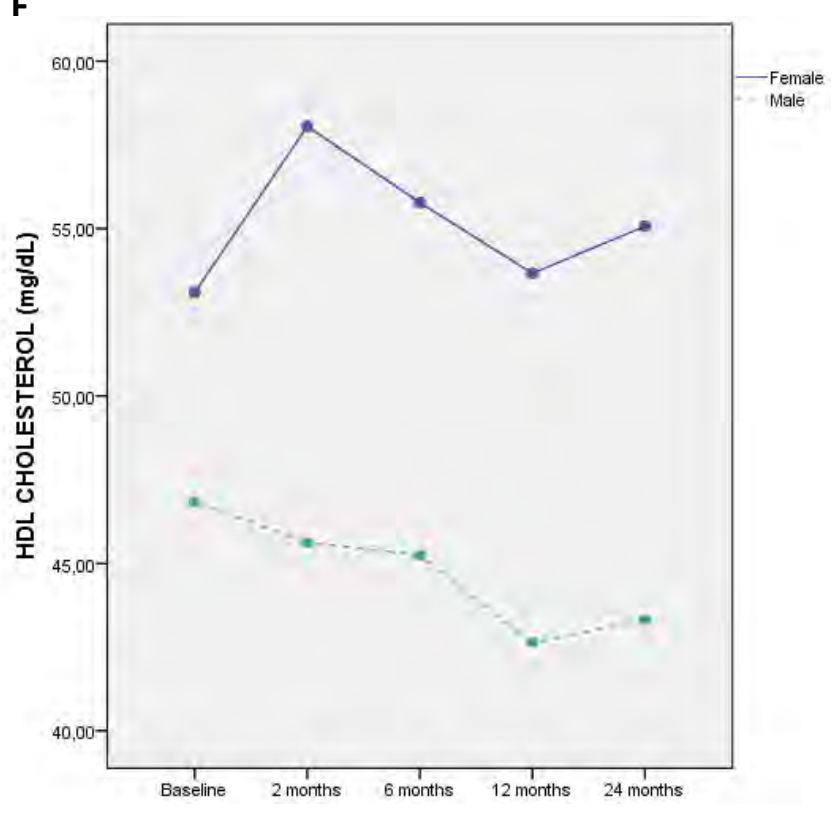

